\title{
As palavras de Landolfi: estado de agitação e sombras
}

Vera Horn

Tommaso Landolfi (1908-1979), escritor italiano nascido em Pico (província de Frosinone), é autor prolífico de contos, romances, teatro, poesia, diários, ensaios, traduções do russo, do alemão e do francês e até de um livro de viagens, "raro tramite in Italia fra tradizione e avanguardia" (Luti, 1975). Visto pela crítica ora como autor extravagante e estrambótico, ora como multifacetado e poliédrico, Landolfi passeou por gêneros diversos, como o fantástico, o gótico, a ficção científica, a fábula, o surrealismo, percorreu diversas estradas, experimentou a releitura de certos gêneros, como a ficção científica, o policial, a fábula. Em toda a sua obra, porém, especialmente na narrativa dos contos, nota-se uma preocupação metaliterária indissociável de sua produção literária e que vai além da autoconsciência textual e aponta para uma reflexão sobre a linguagem em sentido amplo e sobre a criação literária em sentido restrito, com a manifestação, inclusive, de suas perplexidades, suas contradições, suas inconsistências, suas imprecisões e seus espelhos.

É célebre a passagem de "Prefigurazioni: Prato", da coletânea Ombre, de 1954, em que Landolfi anuncia sua relação de amor e terror com as palavras:

pois na época eu tinha uma espécie de amor e terror pelas palavras, religioso e supersticioso (que durou muito tempo), sobre as quais eu concentrava toda a carga de realidade, na verdade, exígua, que conseguia descobrir nos mais diversos objetos do mundo; ou mais simplesmente, as palavras eram quase a minha única realidade. (LANDOLFI, 1991, p. 744-745) (tradução Vera Horn)

\footnotetext{
1 [perché allora io avevo una sorta di religioso, e superstizioso, amore e terrore delle parole (che mi è rimasto poi a lungo), sulle quali concentravo tutta la carica di realtà, invero scarsa, che mi riusciva scoprire nei vari oggetti del mondo; più semplicemente, le parole erano quasi le mie sole realtà]
} 
Esse culto religioso de amor e terror com as palavras acompanhará a narrativa landolfiana como uma marca indelével, no qual ele experimentará toda a sua "carica di realtà", na verdade escassa e desenganada, atribuindo à própria palavra a condição de sua única realidade. A coletânea já evoca no título a condição de sombra que Landolfi entrevia na palavra. As sombras caem sobre as máscaras literárias. Talvez a primeira e mais ameaçadora sombra seja a inscrita na frase que é o princípio de tudo: "No princípio era a palavra", que Landolfi traduz no seu "parola (...) è l'anima del mondo", do conto "Da: l'astronomia esposta al popolo. Nozioni di astronomia sideronebulare", de Il mar delle blatte, 1939. Na verdade, o culto da palavra anunciado em Ombre está em permanente tensão com o estado de insuficiência, que Landolfi anuncia no diário LA BIERE DU PECHEUR, de 1953:

eu poderia dar uma descrição tão exata do meu próprio estado que, portanto, com uma definição quase clínica, deveria chamar de insuficiência. (LANDOLFI, 1991, p. 572). ${ }^{2}$ (tradução Vera Horn)

Landolfi formula esse "stato di insufficienza" em LA BIERE DU PECHEUR (por desejo do escritor é para ser escrito em maiúscula e sem acento para provocar ambiguidade), invertendo o modelo dannunziano de obras como Il secondo amante di Lucreria Buti:

\begin{abstract}
Algumas obras dannunzianas, como por exemplo Il secondo amante di Lucrezia Buti, nos dariam, se não fossem sustentadas por um poderoso engenho, a descrição mais exata daquilo que se chama estado de suficiência. Só invertendo os termos, eu poderia dar uma descrição tão exata do meu próprio estado que, portanto, com uma definição quase clínica, deveria chamar de

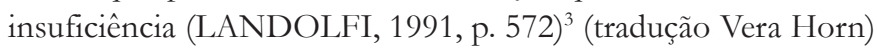

Esses dois polos tensores atravessam a narrativa landolfiana, gerando um constante estado de exasperação da palavra. Como escreveu Pampaloni,

$2[(. .$.$) io darei una pittura altrettanto esatta del mio proprio stato, che pertanto, con definizione quasi$ clinica, dovrei chiamare stato di insufficienza]

3 [alcune opere dannunziane, per esempio Il secondo amante di Lucrezia Buti, ci fornirebbero, se non fossero sostenute da un potente ingegno, la pittura più esatta di ciò che si chiama stato di sufficienza. Solo a roversciarne i termini, io darei una pittura altrettanto esatta del mio stato, che pertanto, con definizione quasi clinica, dovrei chiamare stato di insufficienza] 
por um lado (a cornus artis), a palavra é artifício, resgate, realidade obstinada que se contrapõe à outra realidade. Por outro, e simultaneamente (a cornus exsistendi), é insuficiência, metáfora de prisioneiro, derrotada em sua primeira aparição pela insolente "verdade" da vida. (PAMPALONI, 1987, p. 797). (tradução Vera Horn)

Landolfi acaba por transformar o caráter de insuficiência em uma espécie de cânone de sua poética, cada vez mais orientada no sentido de colher da palavra seu estado de agitação, de ambiguidade, de poder alusivo, de reticência.

Segundo Capek-Habekovic, a fascinação pelas palavras e a sua flexibilidade e infinita possibilidade de mutação, assim como sua capacidade plurissignificativa, constituem um dos principais focos de atenção de Landolfi em sua carreira literária. A fascinação de Landolfi em relação ao léxico confere às palavras posição dominante dentro da composição narrativa. A ênfase não está no seu desenvolvimento dentro de uma "moldura" narrativa, mas na própria palavra, em todos os seus níveis de significação e na dinâmica de sua metamorfose.

Em alguns contos, Landolfi chega a enfrentar a condição mutável e instável do signo linguístico. O estado de calmaria dura pouco para dar lugar a um estado de agitação, de convulsão que toma conta das palavras e as deixa à deriva. De acordo com Capek-Habekovic, "Parole in agitazione" [traduzido como "Palavras em revolta"] constitui o exemplo mais ilustrativo do reino da palavra no discurso narrativo landolfiano (CAPEK-HABEKOVIC, 1995, p. 188).

Os dois contos selecionados para tradução referem-se a essa constante introspecção literária da obra landolfiana, mas é em "Palavras em revolta" que observamos mais nitidamente a posição predominante da palavra na escritura e seu estado de agitação e reticência. No conto "O pai de Kafka", Landolfi transforma o escritor de Praga em personagem (e nesse caso, o conto "La moglie di Gogol" realiza operação similar) com referências implícitas à Metamorfose e à Carta ao pai, criando uma série de elementos para reviver o problemático relacionamento de Kafka com o pai, entre afeto, obsessão, angústia, repúdio e libertação, em uma atmosfera fantástica. A página landolfiana pesquisa, sonda, hábil e criativa, joga com artifícios, e a tradução deve, pois, atentar para a recriação, o jogo, os bastidores da escritura, como no caso desse conto. "Palavras em revolta" constitui um desafio à tradução pela necessidade de recriar em outra língua a relação

4 [da un lato (a cornus artis) la parola è artificio, riscatto, realtà testarda che si contrappone all'altra realtà. Dall'altro lato e contestualmente (a cornus exsistendi) è insufficienza, metafora di prigioniero sconfitta nel suo primo pronunciarsi dall'insolente 'verità' della vita.] 
entre significante e significado que se instaura no conto (em uma época présaussuriana) e a ambiguidade polissêmica que caracteriza as "palavras em revolta". A opção (adotada inclusive pelo tradutor americano) seria deixar as palavras no original e grafá-las em itálico, mas preferimos adotar essa solução, optando pela estranheza de que fala José Paulo Paes, segundo o qual "louvável, na verdade, há de ser a tradução que, sem desfigurar por imperícia as normas correntes da vernaculidade, deixe transparecer um certo quid de estranheza capaz de refletir, em grau necessariamente reduzido, as diferenças de mundo entre a língua-fonte e a língua-alvo" (1990, p. 106). De resto, o próprio Landolfi (que também era tradutor) afirmava que o que se ganha de um lado, perde-se do outro (LANDOLFI, 1971, p. 134).

\section{Contos traduzidos}

\section{Palavras em revolta}

De manhã, quando me levanto, naturalmente escovo os dentes. Por isso, deitei na escova uma cobrinha de pasta de mais ou menos um centímetro e meio, introduzi a escova na boca, esfregando vigorosamente, e então, com a boca ainda cheia de espuma, sorvi um gole de água da torneira. Só estou dizendo isso para mostrar que fiz tudo como de costume.

Enxaguei a boca e cuspi. Mas eis que, ao invés da costumeira baba gosmenta, jorraram elas, as palavras. Não sei como explicar: eram palavras, mas estavam vivas e esguichavam pra lá e pra cá na pia, por sorte, vazia. Uma delas escorregou e quase foi parar no ralo, mas conseguiu se equilibrar e se salvou. Pareciam despachadas e alegres, se bem que um tanto amalucadas: não paravam de rodar feito certos coelhos em cativeiro ou as jovens lontras nas corredeiras. Em seguida resolveram escalar o espelho. Não exatamente o espelho, queriam trepar pela prateleira do espelho e o fizeram perfeitamente, não sei como. Foi então que percebi que também falavam, ou melhor, berravam com uma voz fininha, embora muito baixa para meus ouvidos. Na prateleira, puseram-se a apresentar danças e a fazer gracejos e mesuras como se estivessem numa ribalta; começaram então a gesticular e, pelo que entendi, queriam falar comigo. Agucei o ouvido e aproximei-me, e assim, não sem esforço, pude ouvi-las: e não só, pois como meus olhos tinham se familiarizado com elas, comecei a reconhecer algumas. Na verdade, devia dizer individualizar e ler algumas delas, já que algumas delas eu só conhecia por alto; de qualquer maneira, vi a palavra Locupletá-las, e também Massicoto, Erário, Martelo, entre outras. 
- Nós somos palavras, - começou a dizer Locupletá-las, que parecia a líder.

- Estou vendo - respondi.

- Nós somos palavras e você é um daqueles.

- Daqueles o quê?

- Um daqueles que usa e abusa de nós. Por isso é que viemos procurar você. Nesses tempos de reivindicações, redimensionamentos e outros re, seria o fim da picada que justamente nós ficássemos para trás. Mas, se todas nós juntas apresentássemos nossas reivindicações, estaríamos fritas, então uma coisa de cada vez. Para encurtar a conversa, queremos solicitar uma redistribuição.

- Redistribuição do quê, suas bobinhas?

- Para começar, dos significados. Cada uma de nós tem um significado, não é?

-É, apesar do que andam aprontando certos escritores e jornalistas.

- Então, olha. Eu, por exemplo, sou Locupletá-las, e o que significo?

- Significa mais ou menos relativo à riqueza.

- Pois é, isso porque você sabe; mas e se você não soubesse?

- Mas que pergunta!

- Não, veja bem, eu significo o que você disse, mas você acha isso justo? Eu deveria significar relativo a regato ou a água que corre em geral.

- Mas por quê?

- Meu Deus, Lo-cu-ple-tar, você não tem ouvido?

- Humm. Mas antes de mais nada, você nem existe. Eu conheço Locupletar, Locupletação, Locupletíssimo, mas você... Se você existe, é tão pouco usada que nem sei do que está reclamando...

- Existo, sim, e isso não quer dizer nada.

- Vamos ver, - saltou uma outra - eu sou Fragária -: e então, o que significo?

- Eu é que vou saber?

- Cá pra nós, boa resposta pra quem é um daqueles; mas, por outro lado, tanto melhor. Quero dizer, o que você acha que eu significo, assim por alto?

- Não sei... algo como um penhasco.

- Que nada, é porque você pensou em fraga; deixe as aproximações de lado, senão as coisas ficam mais complicadas ainda. Você tem que tirar da cabeça 
todas as ideias feitas. Então vamos lá, assim à primeira vista, o que é que eu significo?

- Então... acho que é uma espécie de pedregulho ou pavilhão.

- Viu?

- O quê?

- Acontece que eu quero dizer morango. E você acha isso justo?

- E eu - interveio uma terceira - o que você acha de mim? A gente também pode inverter as coisas. Então, olha, eu sou Martelo, você não acha isso uma afronta?

- Pra mim você está falando grego.

- O que é um martelo? Isso você deve saber. Bem, o martelo podia se chamar tudo, menos martelo.

- Ah é, e como deveria se chamar?

- É óbvio: Lula.

- Agora entendo o que você quer dizer, mas não vejo por que isso tenha a ver logo com você. Você é Martelo e, se acha que deve se chamar Lula, está redondamente enganada, porque nesse caso você seria Lula, e não Martelo. Você não passa de uma palavra, infeliz.

- Você não entende nada mesmo - interveio a própria Lula. --É simples: nós duas queremos trocar de significado, e pelo menos isso ficaria resolvido. Não é mesmo, Martelo?

- Nada disso, queridinha! - berrou Martelo. - Como é que é? Você resolveria seu caso, não há dúvida; mas e eu? Eu passaria a designar aquela espécie de molusco... argh! Você está enganada, meu bem. Martelo só pode significar aquela espécie de... de árvore. Uma coisa vegetal.

- Calma - disse. - É verdade mesmo que três galos não cantam num só terreiro.

- Que três o quê, o provérbio fala de dois.

- E vocês estão criando caso como se fossem três. Vejamos, você, Martelo, você mesma não disse que queria se chamar, aliás, que queria ser Lula?

- De jeito nenhum, mas você é uma besta mesmo! Eu só disse que o objeto martelo deveria se chamar Lula, o que é bem diferente.

- Ai, meu Deus, vocês estão fundindo a minha cuca. E então?

- Então é claro que eu não posso trocar meu significado com a Lula, embora a Lula tenha que trocar comigo. Ficou claro? 
- Não.

- Resumindo, é justo que eu dê o meu significado à Lula, mas não quero o dela em troca, ora bolas! Quero o de outra.

- E o de quem, por exemplo?

- Por exemplo, o de... olha ela lá, da Bétula.

- E ela?

- Quem, a Bétula? Ela troca com alguém, o dela não tem muito a ver com ela mesmo. Ela pode trocar com a Trave, por exemplo.

- O quê? - chiou a Trave ao ouvir aquilo. - Você está doida? Pense na sua vida, que na minha penso eu. - E lá vinha briga.

- Eu, Irídio, só posso ser uma lima, é óbvio.

- E eu tenho que ficar com o seu significado? - rebateu Lima.

- Eu, para sua informação, só posso significar uma coisa bem macia, mas nunca um metal, ainda mais tão duro! No máximo, poderia trocar de significado com Travesseiro ou Almofada...

Nessa altura dos acontecimentos todas gritavam e chiavam ao mesmo tempo. Aquilo começava a me doer nos ouvidos. Perdi a paciência.

- Pode-se saber o que vocês têm na cabeça, suas tratantes? -berrei. - Querem ver o que eu vou fazer agora para vocês todas ficarem satisfeitas?

- O que você vai fazer, hein? - zombaram.

- Esperem aí.

Louco de raiva, corri à cozinha e peguei uma garrafa vazia, catei uma folha de papel e um lápis no escritório e voltei.

- Agora vou escrever aqui os significados de cada uma de vocês, depois vou enfiar vocês todas aqui dentro dessa garrafa e no final vocês vão sair dela uma de cada vez. Assim, cada uma vai ficar com o significado que tirar: a primeira que sair pega o primeiro significado, a segunda o segundo e assim por diante. Vamos começar.

Elas não queriam obedecer e ficavam tentando me enrolar, mas obrigueias a dizer bem direitinho cada atributo. Não queriam ser capturadas e escapuliam para lá e para cá; mas dei um jeito de engarrafá-las todas, com a palma da mão fechada em forma de concha e agarrando-as em seguida com o polegar e o indicador da outra mão. Pareciam ratos enjaulados, de tanto que guinchavam. Assim que todas entraram na garrafa, comecei a deixá-las sair uma por uma, como tinha estabelecido; e cada uma, como disse, teve que se contentar com o significado 
que tirou. À medida que saíam, fugiam sabe-se lá pra onde e as perdia de vista. E assim acabou a história.

É, mas agora temos um grande problema. Cada uma delas tirou um determinado significado e ficou com ele, tudo bem, mas como saber que significado tiraram? Esse é o problema. Não sei se consegui explicar direito; vocês estão entendendo? Tudo foi feito na base da amizade, da palavra; com a agitação do momento eu nem pensei em anotar os passos e as atribuições de significado de cada uma; não fiquei com nada, nenhum comprovante. De forma que, pra encurtar, elas sabem o que significam, mas eu não. É terrível.

Além disso, estou meio preocupado. Sim, porque como eu disse, quando elas saíram da garrafa fugiram sabe-se lá para onde, mas devem ter ficado pela casa e, mais dia, menos dia, vocês vão ver, elas vão aparecer.

Nisso tudo, só fiquei feliz com uma coisa: finalmente consegui entender o sentido da expressão "tirar a palavra da boca de alguém".

\section{O pai de Kafka}

Cedendo a instâncias de alguns amigos, contarei brevemente o episódio que teve tanta repercussão na vida do Mestre (e na minha também).

- E se nesse momento, duas, aliás, umas tantas patas, compridas, delgadas e peludas se insinuassem por entre os batentes daquela porta (que só estava encostada); e se a própria porta cedesse à pressão e abrisse devagarinho, dando lugar a uma aranha enorme, do tamanho de um cesto de roupa suja?...

$-\mathrm{E}$ então?

- Espera um pouco, ainda não acabei. Se essa aranha tivesse a cabeça de um homem e começasse a te fitar com insistência? O que você faria? Você não se mataria?

- Eu? Nem pensar. Por que diabos deveria eu me matar? Eu mataria a aranha.

- Pois eu sim, eu me mataria. Meu Deus, onde já se viu isso?

- Eu faria qualquer coisa, menos isso, não, de jeito nenhum.

Kafka nem bem acabara de pronunciar essas palavras e ainda estava olhando para a porta encostada com ar desafiador quando o batente girou lentamente nos eixos e a cena que eu imaginara se deu tal e qual. $\mathrm{Na}$ sala isolada onde estávamos jantando, erguemo-nos sobressaltados. A aranha, ou cabeça humana, avançava em direção à mesa com suas longas patas e nos fitava com uma expressão maligna. 
- E então - gritei, quase chorando, confesso - e então, por que você não a mata agora?

Mas Kafka olhava para o animal, ou homem, com os olhos esbugalhados e não movia um músculo; no entanto, recuava quase sem perceber para outro canto da sala. O fato é que aquela cabeça (como eu soube depois) era a cabeça do pai de Kafka, falecido havia tempo. Ao olhar para o filho, trazia no semblante a pior expressão possível, os olhos injetados de sangue e levemente enviesados, o lábio superior arqueado para um canto em sinal de raiva, como quando costumava fazer aqueles sermões enfadonhos, que Kafka agora lembrava muito bem, erguendo a voz de forma desagradável. Não falava, talvez porque não pudesse, mas tinha ganas de gritar. Tinha o rosto voltado para o alto, a cabeça meio inclinada, feito um sapo.

"Que diabos fiz eu agora?", se perguntava Kafka, tomado pelo sentimento de angústia que experimentava em criança quando era alvo daqueles sermões, sem nem mesmo conhecer o motivo - Papai... - murmurou.

$\mathrm{Eu}$, confesso, limitei-me a bater palmas e gritar esbaforido: fora daqui, fora, brutamontes!, sem coragem para mais nada. Então o pai de Kafka, que até o momento avançara circunspecto em nossa direção, pareceu retroceder e controlar-se (dominar-se na frente de "estranhos" sempre fora seu forte, embora todos pudessem adivinhar-lhe os sentimentos ao olhar-lhe nos olhos, mesmo que nessas ocasiões nem tivesse murmurado entredentes: ora bolas!); adiando a cena, ou a agressão, voltou-se e saiu silenciosamente por onde tinha vindo, com um andar coxo e inseguro. Eu, confesso, fugi para algum lugar, arrancando os cabelos e soluçando; Kafka, pouco depois, precipitou-se no encalço do pai no grande salão escuro.

Seria inútil dizer que não conseguiu mais encontrá-lo naquela noite, nem nos dias seguintes, ainda que o tivesse procurado insistentemente por todos os cômodos. "Mas", disse a si mesmo, "quem diria que um animal como esse albergava-se em minha casa! Quem sabe se há outros desse tipo? Não posso mais viver aqui se não o capturar". Primeiro pensava em trancá-lo em uma jaula ou no quarto que fora dele. Enfim, certo dia, ao crepúsculo, conseguiu vê-lo atravessando rapidamente um depósito cheio de objetos poeirentos e compreendeu que ele passava com facilidade através de portas fechadas e talvez até de paredes. Naquele momento decidiu matá-lo sem piedade, não havia mais o que fazer; mas também perdeu seus rastros naquela ocasião.

Um dia, quando já tinha perdido as esperanças de encontrá-lo e já se dispunha a ir embora e abandonar-lhe inteiramente o velho castelo, ele lhe apareceu 
repentinamente, em plena luz do dia. O futuro grande escritor estava em seu quarto, por cuja janela o sol penetrava com generosidade. Sob a luz do sol pareceu ainda mais cinzento e empoeirado; dessa vez o vulto cinéreo fitava o filho com uma expressão fatigada e quase suplicante, com grande afeto e lágrimas nos olhos (como nos momentos de grande mal-estar). Mesmo assim, Kafka agarrou uma cadeira e o colheu de surpresa, disparou em seguida até o porão para pegar um martelo e o esmagou definitivamente. Da cabeça despedaçada jorrou, como era de se esperar, uma espécie de miolo meio líquido.

Com isso, Kafka acreditava ter ficado livre dele para sempre, ainda que a um preço alto. Mas quantas aranhas, grandes ou pequenas, pode encerrar um velho castelo!

\section{Parole in agitazione}

Al mattino, quando mi levo, naturalmente mi lavo i denti. Sicché stesi sullo spazzolino un vermicciuolo di dentifricio lungo circa un centimetro e mezzo, mi ficcai lo spazzolino in bocca fregando vigorosamente, quindi, colla bocca ancor piena di schiuma, succhiai un sorso dal rubinetto. Dico questo per dire che insomma feci tutto come al solito.

Mi sciacquai la bocca e sputai. Ma ecco che, invece di venir fuori la solita disgustosa miscela, vennero fuori loro, le parole. Non so come spiegarmi: erano parole ma erano vive, e guizzavano qua e là nel lavandino, per fortuna vuoto. Una scivolò e andò quasi a finire nel buco sul fondo, ma si riprese e si salvò. Parevano vispe e allegre, benché un po' pazzerelle; giravano come fanno qualche volta i coniglioli in gabbia o le giovani lontre nelle rapide. Poi decisero di dar la scalata allo specchio. Non proprio allo specchio: volevano inerpicarsi sulla mensola dello specchio, e ci riuscirono benissimo, non so in che modo. E qui mi accorsi che discorrevano anche, o meglio gridavano con un vocino acutissimo, sebbene sempre fievolissimo per le mie orecchie. Sulla mensola fecero un monte di balletti, di lazzi e d'inchini, come "fossero su una ribalta, e poi presero a far dei cenni, da cui capii che volevano parlarmi. Tesi l'orecchio e accostai il viso, e così, non senza sforzo, potetti udirle; non solo, ma, abituandosi il mio occhio, cominciai a riconoscerne alcune. In verità dovrei dire a individuarne o leggerne alcune, giacché molte le conoscevo appena per prossimo; ad ogni modo vidi la parola Locupletale, e Massicotto ed Erario e Martello ed altre.

"Noi siamo parole" prese a dire Locupletale che sembrava la comandante.

"Lo vedo" risposi. 
"Noi siamo parole, e tu sei un di quelli."

"Chi quelli?"

"Un di quelli che ci tratta e bistratta. Ragion per cui è legittimo che proprio a te ci rivolgiamo per giustizia. In questi tempidi rivendicazioni, di ridimensionamenti e consimili ri, la sarebbe buffa che appunto noi restassimo indietro. Ma se presentassimo tutte insieme le nostre rivendicazioni si starebbe freschi: una cosa per volta. In breve, noi chiediamo una ridistribuzione."

"Che ridistribuzione o di che, 'grulline?"

"Dei significati, per cominciare. Ciascuna di noi significa qualcosa o no?"

"Direi, checché facciano taluni romanzieri o giornalisti."

"Ebbene ascolta. Io, per esempio, son Locupletale: e cosa significo?"

"Significhi press'a poco Attinente alla ricchezza."

"Già, perché lo sai; ma se non lo sapessi?"

"Che razza di domanda."

"No, vedi, io significo quello che hai detto, ma ti par giusto? Dovrei invece significare Attinente a ruscello o in genere ad acqua che scorre."

"Ma perché?"

"Perbacco, lo - cu - ple - ta - le: non ce l'hai l'orecchio?"

"Uhm. Ma per prima cosa tu forse non esisti neppure. Io conosco Locupletare, Locupletazione, Locupletissimo, ma te... O se esisti sei così poco usata che di che ti lagni?"

"Esisto, esisto; e se son poco usata non vuol dir nulla."

"Sentiamo," saltò su un'altra "io son Magiostra: e allora, che significo?"

"E cosa ne so!"

"Bravo, tra parentesi, per esser tu un di quelli; ma d'altronde tanto meglio. Dico, a occhio e croce cosa ti sembra che io significhi?"

"Non saprei... un che come un copricapo."

"Ma no, è perché pensi a Magiostrina; lascia perdere gli accostamenti, se no le cose si complicano ancora di più. Devi cercare di metterti di fronte a me senza nessuna speciale idea per la testa. Così, là, alla prima: che significo?"

"Direi allora... una specie di tenda o di padiglione."

"Lo vedi?"

"Che?"

"Invece designo certa fragola molto grossa. E ti par giusto?" 
"E me," interloquì una terza "me dove mi metti? Perché si può procedere anche alla rovescia. Dunque guarda: io son Martello, e non è un vero e proprio sopruso?"

"Per me stai parlando arabo."

"Cos'è un martello, questo lo sai forse. Beh, il martello in tutti i modi dovrebbe chiamarsi fuor che Martello."

"Toh, e come si dovrebbe chiamare?"

"E lampante: Totano."

"Capisco cosa vuoi dire, ma non vedo in che maniera questo riguardi te, proprio te. Tu sei Martello, e se intendi che dovresti chiamarti invece Totano ti sbagli della grossa, perché in tal caso saresti appunto Totano e non Martello: tu non sei che una parola, sciagurata."

"Non capisci proprio nulla" intervenne Totano stessa. "E semplice: noi due vorremmo scambiarci i nostri signiûcati, e almeno "questa faccenda andrebbe a posto. Non è così, Martello?"

"Niente affatto, carina!" urlò Martello. "Come sarebbe? Tu andresti a posto, non c'è discussione; ma io? Io verrei a designare quella razza di Calamaro... puah! T'inganni, bellezza: Martello non può significare altro che qualche sorta di... di albero, ecco. Una cosa vegetale."

"Calma," dissi io "è proprio vero che due femmine e una papera misero un mercato a Napoli."

"Macché due femmine: tre, femmine, dice il proverbio."

“E voi in due state facendo confusione per tre. Vediamo un po':tu, Martello, non hai detto tu stessa che avresti voluto chiamarti, anzi essere Totano?"

"Per nulla, o sei scimunito davvero? Ho detto solo che l'oggetto Martello dovrebbe chiamarsi Totano, il che fa una bella differenza."

"Oh santo cielo, mi fate girare la testa. E allora?"

"Allora niente: io non posso certo scambiare il mio signiûcato com quello di Totano, sebbene Totano debba prendere il mio. È chiaro?"

"No."

"Insomma, io cedo ed è giusto che ceda il mio significato a Totano, ma non voglio il suo in cambio, ohibò! Voglio quello di un'altra."

"E di chi per esempio?"

"Per esempio quello di... guardala lì, di Betulla."

"E lei?" 
"Chi, Betulla? Ne prende un altro da qualche altra, tanto il suo non le si attaglia: lo prende poniamo da Trave."

"Cosa, cosa?" squittì la nominata Trave udendo questo. "Sei pazza? Te pensa ai casi tuoi, ché ai miei ci penso da me." E giù a litigare.

"Io Iridio" riprese una con aria d'importanza "non posso designare che una lima, è manifesto."

"E io dovrei accollarmi il tuo significato?" ribatté Lima. "Io, per tua norma, non posso a mia volta che signiûcare qualcosa di molto soffice; altro che un metallo, e per giunta durissimo! Tutt'al più potrei scambiare significato con Guanciale o con Cuscino..."

Del resto ormai gridavano e squittivano tutte insieme: mi pareva d'avere una manciata di spilli negli orecchi. Persi la pazienza.

"Ma si può sapere che vi siete messe in capo, birbanti?" urlai. "Volete vedere che bella cosina che fo ora, così siam tutti pari?"

"Che fai, che fai?" mi schernirono.

"Aspettate un poco."

Accecato dall'ira corsi in cucina e presi una bottiglia vuota, mentre dallo studio presi un foglio di carta con una matita; e tornai.

"Ora registro qui perbenino tutti i vostri signiûcati, poi vi ficco tutte in questa bottiglia, e da ultimo vi faccio uscire una per una. Così a chi tocca tocca: la prima che esce prende il primo signiûcato, la seconda il secondo e via discorrendo. Lo prende e se ne contenta, le piaccia o no. Avanti, cominciamo."

Non volevano prestarsi e facevano ostruzionismo, cercando d'imbrogliarmi, ma le costrinsi a dichiarare punto per punto l'esser loro. Come non volevano mica lasciarsi acchiappare e scappavano da ogni parte; ma io, chiudendole e schiacciandole sotto la palma a coppo e successivamente afferrandole col pollice e l'indice dell'altra mano, riuscii lo stesso a imbottigliarle tutte. Parevano sorci in trappola, da quanto stridevano lì dentro. Quando ci furon tutte, cominciai a farle uscire una per volta, secondo avevo stabilito; e ciascuna, come dico, dovette contentarsi del significato che le toccò. A misura che uscivano, fuggivano chissà dove e le perdevo di vista. E così finì la storia.'

Già, ma ora c'è un grosso guaio. Perché ognuna di loro prese un certo significato e se lo tenne, d'accordo: però chi appunto prese quel dato significato? Questo è il problema. Non so se mi spiego; capite la questione? Tutto fu fatto all'amichevole, sulla parola; nell'agitazione del momento io non pensai ad annotare $i$ vari passaggi e le varie attribuzioni di significato; a me non è rimasto niente in 
mano, nessun documento probante. Sicché adesso, alle corte, lo sanno loro cosa significano, non io. Ł̀ terribile.

Inoltre sono un tantino preoccupato. Sì, ho riferito che uscendo dalla bottiglia fuggirono chissà dove: ma sempre in casa saranno restate, e un giorno o l'altro, vedrete, mi risalteranno addosso.

Per una cosa sola son soddisfatto: che almeno, finalmente, ho capito il senso dell'espressione "sciacquarsi la bocca con le parole".

\section{Il babbo di Kafka}

Arrendendomi alle insistenze di molti amici, racconterò brevemente l'episodio che tanta influenza doveva avere sulla vita del Maestro (ed anche sulla mia).

Se ora fra i battenti di quella porta s'insinuassero due, anzi alcune, zampe, lunghissime sottili e pelose; e, la porta stessa cedendo alla pressione e aprendosi pian piano, comparisse un enorme ragno, grosso quanto un cesto da bucato?

"Ebbene?"

"Aspetta, non t'ho detto tutto. Se questo ragno avesse al posto del corpo una testa d'uomo che ti guardasse fissamente da terra? Tu che faresti? T'ammazzeresti, no?"

"Io? Io non ci penserei neppure. Perché diamine dovrei ammazzarmi! Piuttosto ammazzerei lui."

“Io sì, io m’ammazzerei. Perbacco, vivere in un mondo dove sono possibili cose di questo genere!"

"E io ti so dire che tutto farei, tranne che ammazzarmi; neanche per sogno".

Non aveva finito Kafka di pronunciare queste parole e guardava ancora in aria di sfida la porta accostata, quando il battente girò lentamente sui cardini e si produsse punto per punto la scena da me immaginata. Nella sala remota dove stavamo cenando, balzammo in piedi esterrefatti. Il ragno, o la testa d'uomo, molleggiando sulle sue lunghe zampe, avanzava verso la tavola e ci guardava con una certa espressione cattiva.

"Ebbene" gridavo io, lo confesso, quasi piangendo "ebbene, perché ora non l'ammazzi?"

Ma Kafka guardava l'animale o l'uomo, cogli occhi sbarrati e non muoveva un dito; se non che andava arretrando insensibilimente verso un angolo della stanza. Quella testa (come seppi poi) era appunto la testa di suo padre, morto 
tanto tempo prima. Questi, guardando Kafka, aveva la sua espressione peggiore, gli occhi iniettati di sangue e quasi torti, il labbro superiore inarcato da una parte in segno di rabbia; come quando faceva le sue tediose scenate, di cui ora Kafka si ricordava benissimo, alzando la voce nella maniera più sgradevole. Ora non parlava, perché forse non poteva, ma quasi scoppiava, era evidente, dalla voglia di gridare. La testa, con la faccia rivolta all'insù, stava un poco inclinata, nella posizione di un rospo.

"Che diamine ho fatto ancora?" si chiedeva Kafka ripreso dall'angoscioso senso di quando, bambino, era fatto segno a quelle scenate senza saperne esattamente il perché. "Papà..." mormorò.

Io, lo confesso, mi misi a battere le palme e a urlare scompostamente: via, via bestiaccia! Senza però avere altro coraggio che questo. Allora il padre di Kafka, che tuttora avanzava circospetto verso di noi, parve ripensarci e far forza a se stesso (dominarsi davanti agli "estranei" era sempre stato il suo vanto, senonché tutti indovinavano i suoi sentimenti solo a guardarlo in viso, se anche non avesse mormorato fra sé, in casi simili, “corno, corno!"); rimandando la scenata, o l'aggressione, si volse e barcollando e arrancando se ne uscì in silenzio da dove era venuto. Io, lo confesso, fuggii strappandoni i capelli e singhiozzando da qualche parte; Kafka dopo un istante si precipitò dietro a suo padre nel grande salone buio.

Inutile dire che né quella notte né i giorni seguenti gli riuscì di ritrovarlo, sebbene lo cercasse per tutte le stanze a tutte le ore. "Ma guarda," si diceva "c'era a casa mia un simile animale e chi l'aveva mai visto! Chissà poi quanti altri ce ne sono dello stesso genere. Se non lo acchiappo non potrò più vivere qui." Sulle prime pensava di chiuderlo in una gabbia o nella camera che era stata la sua. Infine lo vide un giorno, al crepuscolo, che attraversava velocemente uno sgombero pieno d'oggetti polverosi, e comprese anche che passava con facilità attraverso le porte chiuse e forse attraverso i muri. Da allora si disse che l'avrebbe ammazzato senza pietà, non c'era altro da fare; s'intende che anche in tale occasione gli sfuggì.

Un giorno, quando disperava ormai di ritrovarlo e già si proponeva d'andarsene e abbandonargli tutto il vecchio maniero a discrezione, esso gli venne innanzi all'improvviso e in piena luce. Il futuro grande scrittore era nella sua camera da letto, per la cui ûnestra il sole penetrava largamente. Al sole parve più bigio e polveroso; il volto cinereo guardava stavolta al ûgliuolo con un'espressione stanca e quasi implorante e con grande affetto, colle lacrime agli occhi (come quando, prima, si sentiva male). Ciò malgrado Kafka, dato di piglio a una seggiola, lo stordì sul momento ben bene; poi corse in cantina a prendere un maglio da botte e con quello lo schiacciò del tutto. Dalla testa frantumata sgorgò, come di ragione, una specie di midollo più o meno liquido. 
Con ciò Kafka credeva d'essersene liberato per sempre, anche se a duro prezzo. Ma quanti ragni, grossi o piccini, non alberga un vecchio maniero!

\section{Referências}

CAPEK-HABEKOVIC, Romana. "Intertextual self-reflection in the writing strategies of Tommaso Landolfi's fiction”. In: Gradiva, Vol. 6, no 1, 1994-1995. p. 1-7.

HORN, V. Tommaso Landolfi e a ficção narcisista. Dissertação de Mestrado. São Paulo: FFLCH/USP, 2000.

HORN, V. "Una questione di tono: Tradurre Landolfi in portoghese". In: LANDOLFI, I. e PRETE, A. (org.). Un linguaggio dell'anima. Lecce: Manni, 2006. p. 127-136.

LANDOLFI, T. Gogol a Roma. Articoli letterari. Firenze: Vallecchi, 1971.

ID. Opere I (org. Idolina Landolfi). Milano: Rizzoli, 1991.

ID. Opere II. (org. Idolina Landolfi). Milano: Rizzoli, 1992.

LUTI, G. "L' azzardo dell'arte”. In: Sul filo della corrente. Fatti e figure della letteratura italiana del Novecento. Milano: Longanesi, 1975. pp. 192-226.

PAES, J. P. Traducão. A ponte necessária. São Paulo, Ática, 1990.

PAMPALONI, G. “Tommaso Landolfi”. In: Storia della letteratura italiana diretta da Emilio Cecchi e Natalino Sapegno. Il Novecento. Milano: Garzanti, 1987. Vol. 2, p. 508-519. 